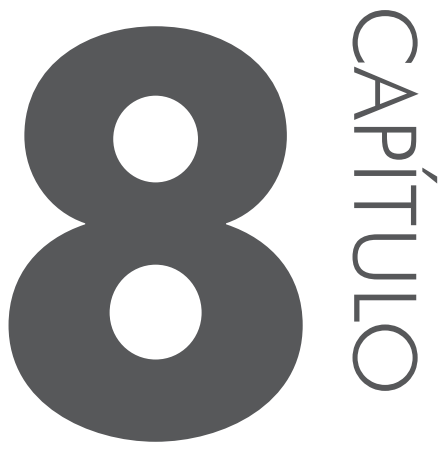

\title{
História em quadrinhos: um gênero para sala de aula
}

Lúcia Maria de Assis ${ }^{1}$ Elyssa Soares Marinho ${ }^{2}$

No final do século XIX, na Europa, surgem as histórias em quadrinhos. Naquele momento, os desenhistas desenvolviam ilustrações para compor um texto sem passagens escritas, somente visual. No Brasil, apesar de os primeiros quadrinhos datarem de 1869, com Angelo Agostini, criador do personagem Nhô Quim em viagem de Minas Gerais à corte no Rio de Janeiro, acredita-se que a revista Tico-Tico, lançada em 1905, tenha sido a primeira a apresentar histórias completas. Essa revista foi lançada pela editora O Malho, no dia 11

1 Doutora em Linguística pela Universidade de São Paulo (USP) e professora adjunta na Universidade Federal Fluminense (UFF).

2 Doutoranda em Linguística pela Universidade Federal do Rio de Janeiro (UFRJ) e professora de Educação Básica na Secretaria Estadual de Educação do Rio de Janeiro. 
de outubro, marcando o início das publicações em quadrinhos dedicadas às crianças no Brasil.

As histórias em quadrinhos consolidam-se, no Brasil e no mundo, como enredos narrados quadro a quadro, com ampla utilização de textos verbais e não-verbais, bem como do discurso direto, característico da língua falada. Constituem-se, portanto, como um gênero discursivo secundário que, de acordo com Bakhtin (1997), aparece, normalmente, em circunstâncias de comunicação cultural na forma escrita e engloba gêneros discursivos primários correspondentes a circunstâncias de comunicação verbal.

Apesar de um gênero extremamente rico, exatamente por unir duas formas textuais (verbal e não verbal), podendo ser bastante explorado no cotidiano escolar, poucos são os professores que dele se utilizam para enriquecer sua prática educativa. É importante que nos atentemos que os PCN (Parâmetros Curriculares Nacionais de Língua Portuguesa) orientam a utilização de vários gêneros discursivos para que se possa formar alunos bons produtores de texto orais e escritos.

Temos, assim, como objetivo apresentar as principais características desse gênero, que pode ser explorado em salas de aula de diferentes disciplinas da Educação Básica. Para isso, tomamos, como pressupostos teóricos, autores que versam sobre a questão dos gêneros discursivos e sua constituição, bem como aqueles que se dedicam especificamente ao gênero história em quadrinhos.

Para atingir nosso objetivo, inicialmente, procuramos esclarecer a definição de gêneros discursivos, apresentando sua composição tipológica. Em seguida, detemo-nos no gênero história em quadrinhos, pormenorizando suas principais características. Por último, esclarecemos por que consideramos importante a utilização desse gênero no trabalho em sala de aula.

\subsection{Gênero discursivo: conceitos e definições}

A utilização eficaz de uma história em quadrinhos em sala de aula para atividades de leitura e produção de textos pressupõe que o professor tenha, inicialmente, conhecimento da abordagem a respeito de gêneros discursivos, uma vez que todo texto é constituído sob determinado gênero. Como mostra Bakhtin (1997, p. 270), "qualquer enunciado considerado isoladamente é, claro, individual, mas cada esfera de utilização da língua elabora seus tipos relativamente estáveis de enunciados, sendo isso o que denominamos gêneros discursivos".

Marcuschi (2008) sinaliza que os gêneros configuram uma área multidisciplinar de estudos, que engloba a análise dos textos e da estrutura discursiva, além de uma descrição da linguagem, tentando responder questões de âmbito so- 
cial, histórico e cultural do uso da língua. O autor lembra que foi na Antiguidade que se iniciou uma observação sistemática do que hoje, chamamos de gênero.

Já Swales (1990, p. 33) afirma que, atualmente, “os gêneros são facilmente usados para referir uma categoria distintiva de discurso de qualquer tipo, falado ou escrito, com ou sem aspirações literárias”. Ou seja, os gêneros são entidades sócio-discursivas e formas de ação social incontornáveis em qualquer situação comunicativa. Surgem emparelhados a necessidades e atividades socioculturais, bem como na relação com inovações tecnológicas.

Seguindo a interpretação dos três estudiosos, Bakhtin, Swales e Marcuschi, podemos afirmar que os gêneros existem em função da necessidade humana de comunicação; ampliam-se e se modificam de acordo com as mudanças ocorridas na sociedade e as diferentes necessidades comunicativas. Assim, é correto afirmar que alguns gêneros se cristalizam formalmente em determinadas necessidades e intenções, como a conversação telefônica, as produções científicas, as notícias de jornal, os classificados e, por que não dizer, as histórias em quadrinhos.

Por outro lado, como a sociedade vai-se modificando, inclusive com força da revolução tecnológica, os gêneros vão sendo ampliados na instauração de novas relações com os usos da linguagem, o que possibilita uma redefinição de alguns aspectos centrais na observação da linguagem em uso, como, por exemplo, a relação entre oralidade e escrita, desfazendo ainda mais suas fronteiras. Isso quer dizer que a necessidade de comunicação e o avanço tecnológico fazem surgir formas comunicativas próprias com certo hibridismo que desafia a velha visão dicotômica ainda presente em muitos manuais de ensino de língua, como pode ser observado num dos gêneros mais comuns entre os jovens atualmente e, por que não dizer, também entre os adultos: as mensagens enviadas por MSN e WhatsApp. São orais ou são escritas?

Como se observa, os gêneros transmutam e abarcam tudo o que é utilizado para a comunicação, o que, por muitas vezes, dificulta a tarefa de sua categorização. Sendo assim, para Bakhtin (1997) importa considerar a diferença essencial que os coloca em duas categorias básicas: a dos gêneros primários e a dos secundários. Os primários são simples e se constituem em circunstância de comunicação verbal espontânea; os secundários são aqueles que, tomando os primeiros, transmutam-nos e aparecem em situações de comunicação cultural mais complexa e mais evoluída, principalmente na forma escrita.

Sobre isso, Rojo (2001) diz que os gêneros primários são próprios da comunicação cotidiana privada e mais próximos da palavra falada. Seriam o material discursivo básico sobre o qual se reelaborariam os secundários, que são próprios das esferas sociais públicas de circulação dos discursos, as quais implicam situações de produção mais complexas. 
Já Marcuschi (2001), ao se referir à dificuldade de categorização dos gêneros, estabelece-lhes três amplos conjuntos: os tipicamente orais, os tipicamente escritos e os produzidos na interface oral/escrito. Sendo assim, é correto dizer que o gênero história em quadrinhos é secundário posto que, em sua elaboração tipicamente escrita, são reempregados recursos de gêneros primitivos, como da conversação oral cotidiana, por exemplo.

A noção de gênero, portanto, pode ser defendida a partir de diferentes perspectivas. Para Marcuschi (2008) importa a premissa de que toda manifestação verbal se dá por meio de textos realizados em algum gênero: "quando dominamos um gênero textual, não dominamos uma forma linguística e sim uma forma de realizar linguisticamente objetivos específicos em situações sociais particulares" (MARCUSCHI, 2008, p. 54). O autor, ainda, salienta que, em certos contextos, o gênero é uma forma de legitimação discursiva situada em uma relação sócio-histórica com motivação sustentada que ultrapassa as motivações pessoais e individuais.

Em relação à história em quadrinhos, vemos que, nesse gênero, procura-se reproduzir uma conversação natural, na qual os personagens interagem face a face, comunicando-se por palavras e expressões faciais e corporais, como informa Eguti (2001). Sendo assim, todo o conjunto do quadrinho é responsável pela transmissão do contexto enunciativo ao leitor. Ou seja, na história em quadrinhos, o contexto é fruto da dicotomia verbal / não verbal, deixando claro que a imagem e a palavra escrita formam um conjunto necessário para a compreensão da história.

Como a linguagem não verbal é tão fundamental quanto a verbal para sua compreensão, não se pode deixar de citar a importância dos elementos específicos de um quadrinho, como requadro, balão, apêndice e legendas na compreensão da narrativa. No dizer de Ramos (2009, p. 14), "ler quadrinhos é ler sua linguagem, tanto em seu aspecto verbal quanto visual (ou não verbal)"; portanto, "dominar essa linguagem, em seus conceitos mais básicos, é condição para a plena compreensão da história e para a utilização dos quadrinhos em sala de aula".

De acordo com Santos e Vergueiro (2012, p. 85), até o formato da história em quadrinhos modifica a maneira como ela deve ser lida. Os autores explicam:

As tiras de quadrinhos, normalmente humorísticas, desenvolvem uma história curta apresentada em uma ou, no máximo, seis vinhetas. Há uma situação inicial e uma reversão das expectativas do leitor (presente no texto ou na imagem), gerando o efeito cômico. Já os quadrinhos publicados em revistas, álbuns ou livros ocupam um espaço maior (de uma a centenas de páginas) e apresentam uma narrativa mais complexa. A leitura de uma página de quadrinhos também é um exercício de percepção mais apurada - embora boa parte das histórias apresente uma estrutura mais tradicional, em que um quadrinho segue o outro horizontalmente e de cima para baixo - há 
histórias que são diagramadas de maneira diferente, forçando o leitor a descobrir a sequência certa de imagens e textos.

A partir dessa noção de gênero discursivo e de que a história em quadrinhos se encaixa num gênero secundário, aborda-se, a seguir, uma pormenorização de suas características, a fim de melhor identificá-la e particularizá-la.

\subsection{Composição do gênero discursivo história em quadrinhos (HQ)}

O gênero discursivo história em quadrinhos compõe-se basicamente de quadros que combinam imagem (linguagem não verbal) e texto (linguagem verbal). Seu veículo é o próprio quadrinho criado para transmitir uma mensagem, ou seja, é uma narrativa exposta quadro a quadro. Sua sequência de ação é obtida por meio do movimento sugerido pela história, o que exige um grande envolvimento do leitor para interpretar e coparticipar da ação.

Segundo Dionísio, Bezerra e Machado (2002, p. 196), “há uma seleção dos quadros a serem sequenciados, o que demanda um trabalho cognitivo maior por parte do leitor" que, ao fazer a leitura, deve construir o fluxo narrativo, formando uma continuidade. Para que isso ocorra na imaginação do leitor, é preciso que haja um código compartilhado entre ele e o autor.

Numa história em quadrinhos existe uma mistura homogênea entre mensagem icônica e linguística. A iconicidade permite que a mensagem seja transmitida visualmente com o máximo de informação e com número reduzido de signos. É nesse sentido que os elementos iconográficos que compõem uma história em quadrinhos constituem um verdadeiro repertório simbólico, podendo ser considerados como uma semântica dos quadrinhos. Esses elementos são os balões, as legendas e o requadro.

Nos quadrinhos, os diálogos são escritos dentro de balões que apresentam diferentes formatos, geralmente, semicirculares e desenhados em linha contínua. O balão se liga à boca do personagem pelo apêndice, o que mostra ao leitor quem está pronunciando as palavras. $\mathrm{O}$ apêndice é semelhante a uma pequena cauda e funciona como um travessão que introduz o texto escrito. Para Eguti (2001), os traços do balão limitam visualmente a fala ou os sons emitidos pelos personagens, e é em seu interior que se localiza a maioria da trama da HQ. Nele, podem-se encontrar tanto palavras quanto sinais, desenhos ou grafemas que correspondem a uma ideia, sonhos ou pensamentos, contribuindo com a dinâmica da leitura e causando impacto à ação.

Quando os balões apresentam-se encadeados ou duplicados, significa que um único personagem está falando seguidamente e, nesse caso, a presença de apêndices 
entre os balões serve para indicar uma pausa entre uma fala e outra. É necessário ressaltar que o formato dos balões é de certa forma inesgotável, considerando a liberdade que o quadrinista tem de explorar todas as possibilidades de apresentação de uma HQ. Os balões mais utilizados são o balão-fala, que geralmente se apresenta com formato semelhante a um círculo; o balão-pensamento, que possui o formato semelhante a uma nuvem; o balão-cochicho, que apresenta linhas pontilhadas; e o balão-grito, cujo formato é irregular, como a representação gráfica de uma explosão, indicando que o personagem emite berros e gritos de irritação, horror ou espanto.

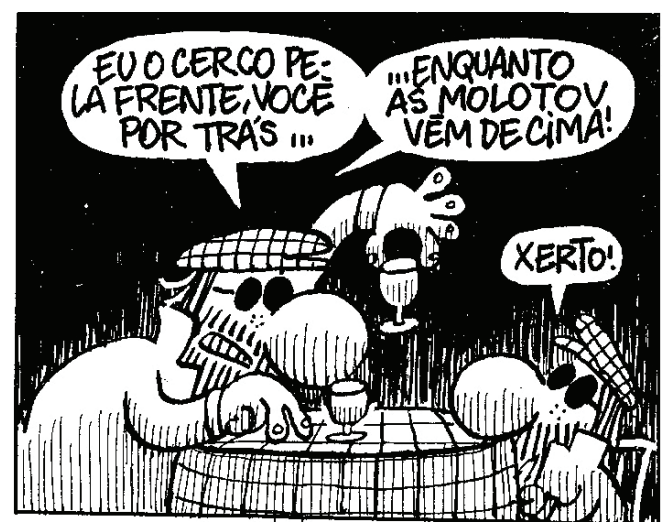

Figura 8.1 - Meia oito, personagem da revista Chiclete com Banana. Exemplo de balão-fala encadeado. Fonte: Angeli (1986).

As legendas são elementos frequentes nos quadrinhos; apresentam a voz do narrador, ou seja, uma voz exterior, que descreve um fato importante de forma impessoal. Em geral, as legendas apresentam-se em pequenos trechos do discurso narrativo, dentro de um quadro ou retângulo. Sua posição no quadrinho varia, podendo ser localizada, conforme aspectos estéticos, ou conforme a preferência do quadrinista. Sua utilização não é uma regra, sendo que, dependendo da extensão do enredo, tal elemento torna-se dispensável.

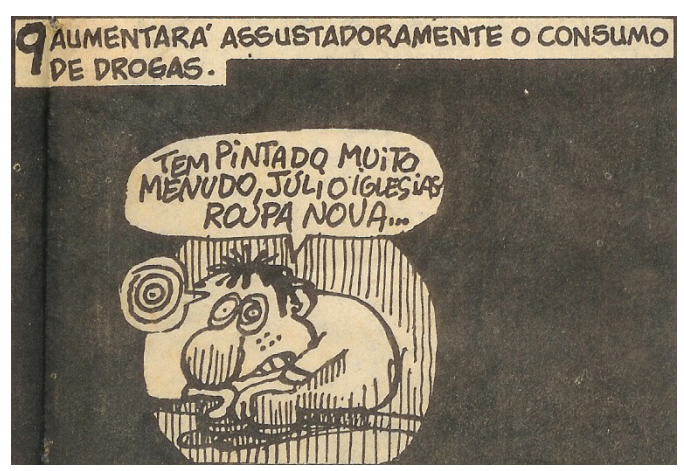

Figura 8.2 - Angeli em uma das 10 previsões para 0 ano de 1986. Exemplo de legenda. Fonte: Angeli (1987). 
O requadro é a linha que envolve cada quadrinho, funcionando como uma moldura para o desenho. É um elemento que ajuda a transmitir emoções e sensações ao leitor. É criado de acordo com a ação desenvolvida na história. Sua forma e tamanho variam de acordo com a criatividade dos quadrinistas, sendo mais comuns os requadros com linhas contínuas e com linhas onduladas, que podem indicar um flash-back da ação ou imaginação de um personagem. A ausência do requadro tem como objetivo transmitir a sensação de espaço ilimitado.

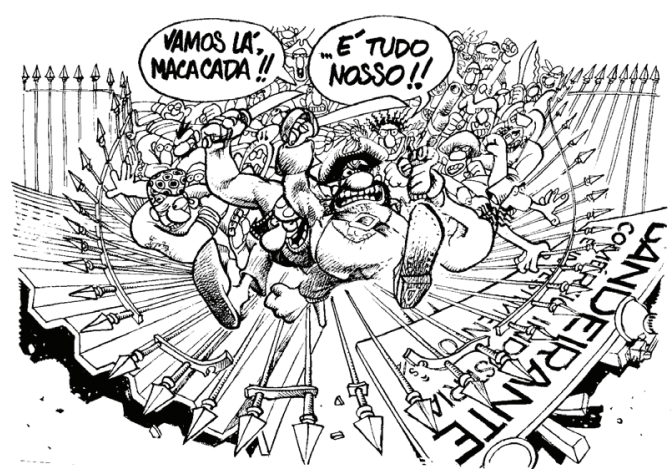

Figura 8.3 - Sátira da conquista dos Bandeirantes feita por Angeli. Exemplo de ausência de requadro.

\subsection{Os recursos linguísticos, não verbais e paralinguísticos dos quadrinhos}

A narração de uma história é o objetivo principal de uma história em quadrinhos. Para isso, são utilizadas imagens, diálogos, gestos, expressões faciais, linguagem popular etc., o que torna a narrativa uma verdadeira representação de situações de fala. Considere-se, entretanto, que o texto verbal dos quadrinhos não é espontâneo, apesar de tentar reproduzir uma conversação natural entre dois falantes. Eguti (2001), diz que o texto da HQ é previamente preparado; nele não se percebem as repetições e redundâncias próprias da oralidade, uma vez que há uma elaboração prévia, assim como acontece com um texto literário.

O discurso direto caracteriza-se pelos enunciados que reproduzem textualmente a fala de alguém. Podemos dizer que discurso direto é aquele em que o personagem é chamado a representar as próprias palavras. No texto escrito, há verbos de elocução (afirmou, respondeu) que indicam a pessoa que fala, que são seguidos por dois pontos (:) ou ponto e vírgula (;). Há também o uso de travessão que indica visualmente o início da frase enunciada. Eguti (2001) observa que o discurso direto nos quadrinhos aparece como uma representação visual das palavras enunciadas nos balões. 
O balão substitui o travessão; a fala nele contida dá a impressão de que os personagens estão produzindo o diálogo no exato momento da leitura, ou seja, o sentido vai-se construindo online. Como não há verbos de elocução, que no texto escrito traduzem o estado psíquico dos personagens, o formato do balão é uma tentativa de realizar tal estado emocional dos personagens.

Um recurso utilizado com frequência pelos quadrinistas é a onomatopeia, uma das principais características da HQ. A apresentação das onomatopeias nas histórias em quadrinhos pode ocorrer fora dos balões, representando sons emitidos por animais, socos, pontapés etc.; pode também aparecer dentro dos balões, representando algum som que os personagens possam emitir dentro do diálogo. Quando estão fora dos balões, contribuem para a visualização dos quadrinhos.

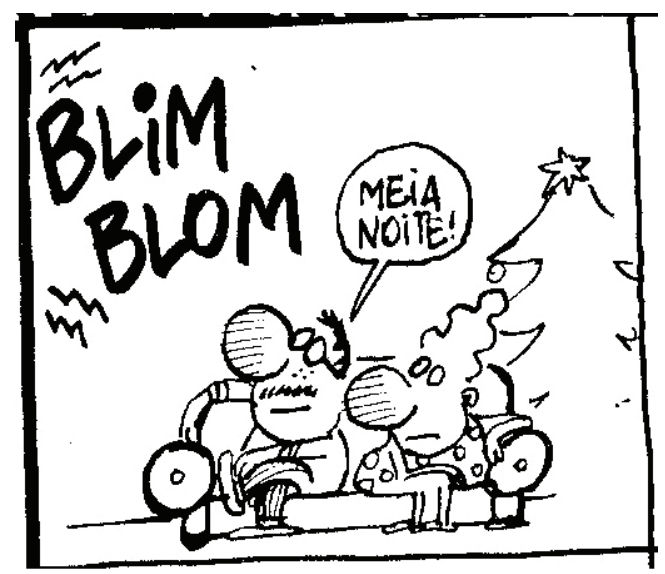

Figura 8.4 - Onomatopeia apresentada fora do balão.

Outro recurso linguístico é a gíria, um fenômeno sociolinguístico que revela diferenças sociais existentes nos agrupamentos humanos. É, sobretudo, na linguagem oral que as gírias estão presentes e, com o passar do tempo, a própria língua escrita começa a registrar tais palavras e expressões.

Além dos recursos linguísticos, há, na HQ, os recursos não verbais (gestos, expressão facial e corporal), que transmitem ao leitor o código de comunicação não verbal. Sendo assim, importa considerar que a expressividade dos personagens não é encontrada somente nas falas, mas também na realidade extralinguística dos quadrinhos, que procuram descrever os gestos dos personagens, de forma que se aproximem o máximo da realidade, tornando-se verdadeiros narradores da história. Tais recursos são ações corporais que expressam um significado, paralelamente às falas, que transmitem verbalmente apenas parte da mensagem.

$\mathrm{Na}$ língua falada, são frequentes as ocorrências de prolongamentos, intensificação de sons e diferentes entonações, conhecidos como ocorrências para-lin- 
guísticas. $\mathrm{Na} \mathrm{HQ}$, esses recursos são representados a partir dos diversos tipos e formas de letras utilizados nos diálogos. Nos quadrinhos, os prolongamentos são frequentes e representados de forma visual. O quadrinista repete as letras das palavras que correspondem aos sons prolongados. Eguti (2001) ressalta que tais repetições podem ser realçadas por outros recursos, como o tamanho dos caracteres, o tipo de letra, a cor utilizada, a espessura da linha, entre outros. O tom de voz e a entonação das palavras também são representados visualmente. Para mostrar que um personagem está gritando, por exemplo, os quadrinistas costumam escrever as falas em letras maiúsculas ou até em negrito.
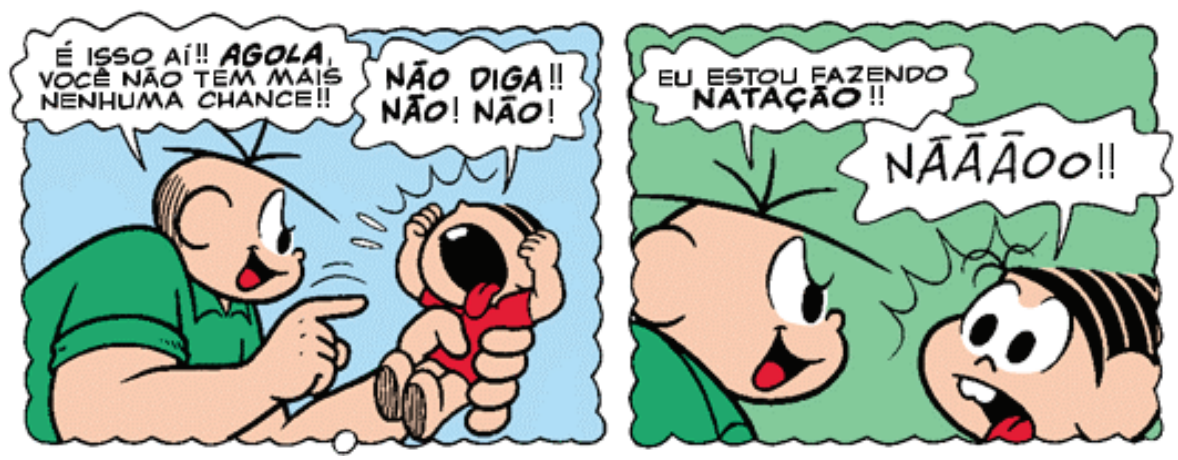

Figura 8.5 - Turma da Mônica. Exemplo de tom de voz elevado e prolongamento. 0 "nãããoo!!" está escrito com letra maiúscula. Fonte: Sousa (2003).

\subsection{0 que tudo isso tem a ver com o ensino?}

O que aqui se expõe, permite-nos observar que as histórias em quadrinhos têm muito a oferecer como objeto de estudo textual em sala de aula, devido à riqueza de seu texto, alcançada pelo amplo uso de linguagem verbal e não-verbal e aspectos composicionais que refletem o modo como as pessoas se organizam, pensam e vivem.

Sua utilização permite, conforme o que expõe Dell'Isola (2007), trabalhar com a retexualização: o processo de transformação de um gênero textual em outro. Nesse caso, o trabalho se realizaria a partir da refacção e reescrita do texto do gênero HQ em outro que também sirva para veicular/comunicar as informações constantes no texto original. $\mathrm{O}$ interessante desse tipo de atividade, em especial com o gênero HQ, é que tudo aquilo que a imagem comunica precisará ser colocado em palavras, o que exigirá um grande aprendizado reflexivo do alunado.

Possivelmente, a depender do novo gênero escolhido, o discurso direto, predominante na HQ, precisará ser transformado em indireto ou desaparecerá. Essa 
atividade exigirá dos educandos não só o conhecimento de, pelo menos, dois gêneros (HQ e o novo escolhido), como também da gramática dos gêneros, do suporte que normalmente os carrega e da função a que tais gêneros se destinam, uma vez que essas características determinarão, inclusive, o grau de formalidade que deverá ser empregado no uso da linguagem.

É importante ressaltar que o gênero HQ pode ser empregado, também, como objeto de estudo de maneira mais ampla. Por exemplo, é possível, por meio da leitura desse gênero, conhecer um pouco do período em que a ditadura militar se impôs no Brasil. Para isso, podemos analisar a HQ produzida pelo jornal Folha de S. Paulo, no caderno Folhinha, que trouxe a público, em 2014, A ditadura em quadrinhos, na qual empregava os recursos do gênero HQ para contar de maneira mais simplificada e divertida o que acontecera naquele período.
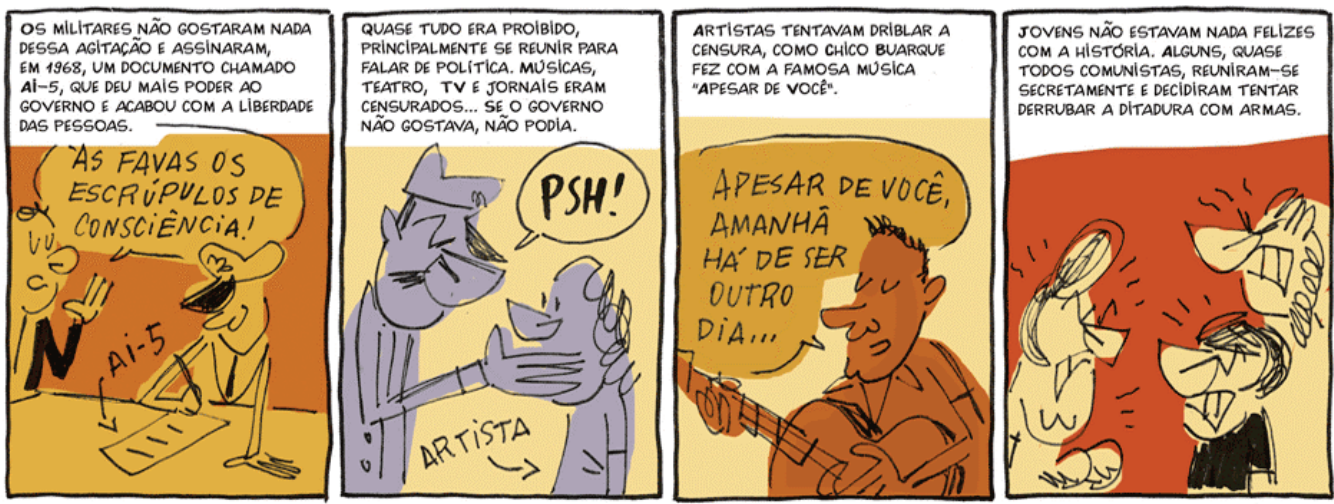

Figura 8.6 - A ditadura em quadrinhos. Fonte: Colombo, Ferraz e Galhardo (2014).

Assim, podemos afirmar que o gênero história em quadrinhos deve ser utilizado em sala de aula, uma vez que tal prática condiz com a nova proposta de ensino que enfatiza conceitos do campo da linguística e está voltada para o ensino de gêneros, iniciando-se por aqueles que façam parte da realidade do aluno. Observa-se, ainda, que a atividade de leitura e produção de textos que toma como base o gênero HQ promove o desenvolvimento do hábito de leitura, amplia o vocabulário do aluno, faz com que ele utilize a imaginação e o raciocínio lógico, colabora para a promoção de sua criticidade e amplia sua participação em sala de aula.

\section{Referências}

ANGELI. Chiclete com Banana. São Paulo: Circo Sampa, 1986.

ANGELI. Chiclete com Banana. São Paulo: Circo Sampa, 1987.

BAKHTIN, M. Estética da criação verbal. 2. ed. São Paulo: Martins Fontes, 1997. 
COLOMBO, S.; FERRAZ, L.; GALHARDO, C. A ditadura em quadrinhos. Folha de S. Paulo, São Paulo, 29 mar. 2014. Folhinha. (Editoria de Arte/Folhapress).

DELL'ISOLA, R. L. P. Retextualização de gêneros escritos. Rio de Janeiro: Lucerna, 2007. DIONÍSIO, A. P., BEZERRA, M. A., MACHADO, A. R. Um gênero quadro a quadro: a história em quadrinhos. In: . Gêneros textuais e ensino. Rio de Janeiro:

Lucerna, 2002.

EGUTI, C. A. A representatividade da oralidade nas histórias em quadrinhos. 2001. Dissertação (Mestrado) - Faculdade de Filosofia, Letras e Ciências Humanas, Universidade de São Paulo, 2001.

MARCUSCHI, L. A. Da fala para a escrita: atividades de retextualização. São Paulo: Cortez, 2001.

. Gêneros Textuais: definição e funcionalidade. In: DIONÍSIO, A. P.;

MACHADO, A. R.; BEZERRA, M. A. Gêneros textuais e ensino. 2. ed. Rio de Janeiro: Lucerna, 2002.

. Produção textual, análise de gêneros e compreensão. São Paulo: Parábola, 2008.

MARINHO, E. S. Histórias em quadrinhos a oralidade em sua construção. In:

Congresso Nacional de Lingüística e Filologia, 8., 2004, Rio de Janeiro. Cadernos... Rio de Janeiro: Círculo Fluminense de Estudos Filológicos e Lingüísticos, 2004. v. 2. n. 12. cap. 11. Disponível em: <http://www.filologia.org.br/viiicnlf/anais/caderno12-11.html>. Acesso em: 30 abr. 2015.

. A construção do cômico nas histórias em quadrinhos da revista Chiclete com Banana. In: JORNADAS INTERNACIONAIS DE HISTÓRIAS EM QUADRINHOS ECA/USP, 1., 2011, São Paulo. Anais... Campinas: Zarabatana Books, 2011. v. 1. p. 99. RAMOS, P. A leitura dos quadrinhos. São Paulo: Contexto, 2009.

ROJO, R. Letramento escolar, oralidade e escrita em sala de aula: diferentes modalidades ou gêneros do discurso? In: SIGNORINI, I. Investigando a relação oral/ escrito. Campinas: Mercado de Letras, 2001.

SANTOS, R. E.; VERGUEIRO, W. Histórias em quadrinhos no processo de aprendizado: da teoria à prática. EccoS, São Paulo, n. 27, p. 81-95, jan./abr. 2012.

SOUSA, M. Cebolinha em o novo plano. Disponível em: <www.turmadamonica.com.br>. Acesso em: 26 jul. 2003.

SWALES, J. M. Genre analysis. Cambridge, Reino Unido: Cambridge University Press, 1990. 
